\title{
Effect of biochar on the unsaturated hydraulic conductivity of two amended soils**
}

\author{
Karolina Villagra-Mendoza ${ }^{1}$ * and Rainer Horn ${ }^{2}$ \\ ${ }^{1}$ School of Agricultural Engineering, Instituto Tecnológico de Costa Rica, 159-7050 Cartago, Costa Rica \\ ${ }^{2}$ Institute for Plant Nutrition and Soil Science, Christian-Albrechts University Kiel, Hermann Rodewaldstr. 2, 24118 Kiel, Germany
}

Received December 15, 2017; accepted May 15, 2018

\begin{abstract}
Water and solute transports in the vadose zone depend on the distribution, size, shape and configuration of the pores. They affect the soil hydraulic properties and, consequently, the directly related processes such as water storage, infiltration, groundwater recharge, and also erosion and runoff. Soils amended with biochar are prompt to improve their physical and hydraulic properties. Biochar addition alters not only porosity, the water retention pattern and the derived pore distribution, but also the hydraulic conductivity under saturated and unsaturated conditions. In our work, two different doses (2.5 and 5\% dry wt.) were added to two textured soils (sand and sandy loam). The unsaturated hydraulic conductivity and saturated hydraulic conductivity were measured under laboratory conditions. The obtained results show the positive effect of biochar on the hydraulic functions. For the sandy soil, the higher the dose of biochar, the more constant and relatively higher is the hydraulic conductivity up to - $40 \mathrm{kPa}$. At less negative matric potentials $(<-10 \mathrm{kPa})$, the unamended sandy loam soil showed a slightly higher unsaturated hydraulic conductivity, compared to the amended soils. These results underline that biochar addition enhances the transport of water under unsaturated conditions by reducing the formation of larger pores while also intensifying the finer inter-particle pore formation.

Keyw ords: amendment, biochar, pore size distribution, texture, unsaturated hydraulic conductivity
\end{abstract}

\section{INTRODUCTION}

Hydraulic conductivity in soils depends on texture, structure and pore properties (configuration, size, shape and distribution). Soils with large pore diameters drain off first, and react as a barrier to water flow at more negative matric potentials. At saturation, coarse textured soils conduct

*Corresponding author e-mail: kvillagra@tec.ac.cr

**This work was partialy supported by IPSWaT Program of the Ministry of Education and Research (BMBF) of Germany, and the Academic Affairs Vice-presidency of the Costa Rica Institute of Technology (2017). water more rapidly than finer textures (Jury and Horton, 2004). The same occurs for aggregated soils as compared with poorly aggregated ones. The opposite occurs under unsaturated soil conditions. Due to their larger pores, coarse-textured soils become nonconductive as matric potential develops as this steeply decreases the hydraulic conductivity. In contrast, in fine textured soils, smaller pores dominate, conducting less water, but doing so more constantly up to more negative matric potential values. Thus, the hydraulic conductivity does not decrease as steeply as for coarse soils. Irrespective of the pore diameter, tortuosity affects the hydraulic conductivity in finer textured soils as it decreases the water fluxes and keeps it constant at a more negative matric potential. Hence, the more tortuous the pores are, the more the water flux is retarded. Both under saturated and unsaturated conditions, a strong dependency is especially noted with regard to this, and must be included in the water flux discussions, which may result in nonlinear functions of water content $(\theta)$ or matric potential ( $\psi$ ) (Hillel, 1998; Jury and Horton, 2004; Selker et al., 1999). Under in-situ conditions, shrinkage/ swelling, mechanical deformation, plowing, biological and chemical processes must be considered as additional components, as they may induce intense changes in the soil medium (Nimmo, 2004). Shrinkage/swelling contributes to the orientation of soil particles, thus affecting the formation of macro pores (enlarged by shrinkage and decreased by swelling), and the formation of aggregates within an intra-aggregate pore system. Its reformation enhances the contact between aggregates and keeps the pores more conductive near saturation.

(C) 2018 Institute of Agrophysics, Polish Academy of Sciences 
Intra-aggregate porosity and its hydraulic conductivity also affect the soil fluxes. During the initial formation of aggregates, new finer pores are formed. These, together with more contact points between the single particles, promote a smaller flux, while a more homogeneous and greater flux occurs after aggregate formation, together with a more continuous macroscopically homogeneous pore system reaching the final stage of the smallest entropy (Horn, 1994). As with all fluxes, the hydraulic conductivity must be considered as a tensor with direction dependent values. Dörner and Horn (2009) described these interactions and concluded that isotropic conditions are less frequent to be seen, while vertical or horizontal anisotropic flux conditions dominate in prisms, and in blocky or platy structures.

The addition of biochar as an amendment positively influences various soil-specific physical, hydraulic and chemical properties, as well as several soil processes (Uzoma et al., 2011; Verheijen et al., 2010). It modifies the pore size distribution and increases the available water for plants, as well as the air capacity (Ajayi and Horn, 2016; Bodner et al., 2013). Moreover, it increases the specific surface area and, consequently, increases the filter and buffer capacity of the soil (Burrell et al., 2016; Eibisch et al., 2015; Uzoma et al., 2011). Some authors have identified a decrease in the saturated hydraulic conductivity $\left(K_{\text {sat }}\right)$ in coarse-textured soils, and the opposite effect in finer-textured soils (Ajayi and Horn, 2016; Brockhoff et al., 2010; Herath et al., 2013; Lim et al., 2016). Castellini et al. (2015) found that near saturation $(-0.1$ to $-1.2 \mathrm{kPa})$, biochar had a negligible effect on the unsaturated hydraulic conductivity of the soil. Kameyama et al. (2012) evaluated the effect of biochar addition on unsaturated hydraulic conductivity $\left(K_{u}\right)$ and observed that the amended soil (up to 3\% biochar) had the lowest values of $K_{u}$ for matric potentials greater than $-10 \mathrm{kPa}$. In contrast, with biochar additions of 5 and $10 \%$, $K_{u}$ displayed higher values than in the unamended soil in the entire matric potential range. Bayabil et al. (2015) observed that charcoal incorporation increased the relative hydraulic conductivity $\left(K_{r e l}\right)$ of fine textured degraded soils, at matric potentials greater than $-10 \mathrm{kPa}$, and Hardie et al. (2014) reported that the addition of biochar to a sandy loam soil increased near saturation at -0.25 and $-0.10 \mathrm{kPa}$. Finally, Uzoma et al. (2011) observed that $\left(K_{\text {rel }}\right)$ increased in the amended sandy soils, but it depended on the pyrolysis temperature and the dosage applied.

The objective of this work was to study the effect of the addition of two biochar dosages on unsaturated hydraulic conductivity and water retention, and the effect that it may have on water transportation through the soil matrix under drying conditions. We tested the hypothesis that biochar addition enhances soil water retention, by increasing the unsaturated hydraulic conductivity at more negative matric potentials.

\section{MATERIALS AND METHODS}

Two soil textural classes were used, i.e. sand (S) and a sandy loam (SL), collected in Schleswig-Holstein, in the northern region of Germany. The sandy loam soil was first air dried and passed through a $2 \mathrm{~mm}$ sieve. The sand had a dominant particle size distribution of 2-0.063 mm. Mango wood, acting as biochar material, was pyrolysed at a temperature of about $600^{\circ} \mathrm{C}$. After crushing, it was passed through a $63 \mu \mathrm{m}$ sieve and added to both the sand and sandy loam in fractions of 2.5 and $5 \%$ (by dry mass). Treatments were set as sand $+0 \%$ biochar $($ control $=\mathrm{S} 0)$, sand $+2.5 \%$ biochar (S2.5), sand $+5 \%$ biochar (S5), sandy loam $+0 \%$ biochar (control $=$ SL0), sandy loam $+2.5 \%$ biochar (SL2.5) and sandy loam $+5 \%$ biochar (SL5). For each treatment, the dry bulk density $\left(\rho_{d}\right)$ was assessed using the soil core method (Soil Survey Staff, 2014), while pH was measured in a $0.01 \mathrm{M} \mathrm{CaCl}_{2}$ solution and the specific surface area was ascertained via the Multipoint Brunauer Emmett-Teller (BET) method (method description can be found in Ajayi and Horn, 2016).

A soil water retention curve was established by way of 40 replications per treatment. In so doing, the samples were packed in $100 \mathrm{~cm}^{3}$ stainless steel cylinders (about $4 \mathrm{~cm}$ height and $5.6 \mathrm{~cm}$ diameter) using an Instron 5569 loading frame (Instron, 2008). Additionally, 10 samples of about $2 \mathrm{~cm}$ diameter for each treatment were prepared for dehydration at $-1500 \mathrm{kPa}$. Some basic soil properties are listed in Table 1.

Soil samples were saturated with water by capillary rise for $48 \mathrm{~h}$, and then drained to matric potentials of $-3,-6,-15$, -30 and $-50 \mathrm{kPa}$. A sand bed was used for water desorption up to $-6 \mathrm{kPa}$, while for more negative matric potentials, ceramic plates were employed. Gravimetric water content was determined by weighing each soil sample at each matric potential. After the last matric potential, samples were oven dried at $105^{\circ} \mathrm{C}$ for $16 \mathrm{~h}$ (Soil Survey Staff, 2014). The gravimetric water content at the matric potential of $-1500 \mathrm{kPa}$ was obtained by saturating the small rings, draining them for about four weeks on ceramic plates under air pressure and, after weighing, letting them dry at $105^{\circ} \mathrm{C}$ for $16 \mathrm{~h}$.

Additionally, 10 samples per treatment $\left(100 \mathrm{~cm}^{3}\right.$ cylinder) were prepared so as to determine the saturated hydraulic conductivity $\left(K_{\text {sat }}\right)$ as measured via the falling-head method (Hartge, 1966). Water flow over time through each soil sample was replicated three times (at three upper and lower gradient limits), and the geometric mean was calculated for the 10 samples corresponding to each treatment.

The unsaturated hydraulic conductivity $\left(K_{u}\right)$ was determined through a modification of the Evaporation method (Hartge and Horn, 2009). Soil samples (three replicates per treatment) were packed in $472 \mathrm{~cm}^{3}$ stainless steel cylinders (about $6 \mathrm{~cm}$ in height and $10 \mathrm{~cm}$ in diameter) and put on a metal plate. At the bottom of each cylinder, an 
Table 1. Physical and $\mathrm{pH}$ properties of sand and the sandy loam soils, as well as their amendments at 2.5 and $5 \%$ biochar addition

\begin{tabular}{|c|c|c|c|c|c|c|}
\hline \multirow{3}{*}{ Treatment } & & article size (\% & & \multirow{3}{*}{$\begin{array}{c}\rho_{d} \\
\left(\mathrm{~g} \mathrm{~cm}^{-3}\right)\end{array}$} & \multirow{3}{*}{$\mathrm{pH}$} & \multirow{3}{*}{$\begin{array}{c}\text { Multipoint } \\
\text { BET-SSA } \\
\left(\mathrm{m}^{2} \mathrm{~g}^{-1}\right)\end{array}$} \\
\hline & $\begin{array}{c}\text { Clay } \\
<0.002\end{array}$ & $\begin{array}{c}\text { Silt } \\
0.063-0.002\end{array}$ & $\begin{array}{c}\text { Sand } \\
2.0-0.063\end{array}$ & & & \\
\hline & \multicolumn{3}{|c|}{$(\mathrm{mm})$} & & & \\
\hline S0 & 1 & 0 & 99 & & 7.5 & $0.3 \pm 0.1 \mathrm{a}$ \\
\hline $\mathrm{S} 2.5$ & 0 & 1 & 99 & 1.5 & 7.5 & $0.5 \pm 0.2 \mathrm{a}$ \\
\hline S5 & 1 & 0 & 99 & & 7.5 & $1.5 \pm 0.2 b$ \\
\hline SL0 & 13 & 33 & 54 & & 6.8 & $4.7 \pm 0.5 c$ \\
\hline SL2.5 & 13 & 33 & 54 & 1.4 & 7.0 & $4.0 \pm 0.1 \mathrm{~d}$ \\
\hline SL5 & 12 & 34 & 54 & & 7.1 & $4.7 \pm 0.2 c$ \\
\hline Biochar & & & & & 7.1 & $42.1 \pm 0.7$ \\
\hline
\end{tabular}

$\rho_{d}-$ bulk density, BET-SSA - specific surface area. Particle size distribution according to German Standards (AG Boden, 2005). Variables with the same letters are not significantly different $(\mathrm{p}<0.05)$.

o-ring sealed the soil cores and prevented both evaporation and water leakage from the sample. Thus, water loss only occurred from the top surface by way of a continuous horizontal air flow and was registered by TDR mini probes and micro tensiometers installed horizontally at two different depths. Soil water content $\left(\theta, \mathrm{cm}^{3} \mathrm{~cm}^{-3}\right)$ and matric potential $\left(\psi_{m}, \mathrm{kPa}\right)$ were monitored continuously by a real-time computer. Tensiometers were lined with Kaolinite in order to guarantee good soil-sensor contact. Before undertaking the measurements, the samples were saturated.

The unsaturated hydraulic conductivity was obtained according to the transformed Darcy's equation:

$$
K_{u}=\frac{1}{t_{1}-t_{2}} \quad \frac{\overline{\Delta \theta}}{\overline{\text { grad } \psi_{m}}},
$$

where: $K_{u}$ is the unsaturated hydraulic conductivity $\left(\mathrm{cm} \mathrm{s}^{-1}\right)$, $t_{1}-t_{2}$ is the time interval between two measurements (s), $\overline{\Delta \vartheta}$ is the change of soil water content between two measurements $\left(\mathrm{cm}^{3} \mathrm{~cm}^{-3}\right), \operatorname{grad} \psi_{m}=\frac{\psi_{2}-\psi_{1}}{l}$ is the hydraulic gradient between two points, $l$ is the flow length $(\mathrm{cm})$.

Due to the nature of the laboratory method, the observed $K_{u}$ values were obtained within a small matric potential range. Therefore, the observed hydraulic properties at different matric potential values were fitted using van Genuchten-Mualem's expression (van Genuchten, 1980) by means of RETC software (van Genuchten et al., 1991), which is known to generate a good data fit for the hydraulic properties of unsaturated soils (Neyshabouri et al., 2010; Van Genuchten and Nielsen, 1985; Wessolek et al., 1994). The fitted curves were used to predict the curve pattern in a wider matric potential range:

$$
K_{u}=K_{\text {sat }} \frac{\left[1-\left(\alpha\left|\psi_{m}\right|\right)^{n-1}\left(1+\left(\alpha\left|\psi_{m}\right|\right)^{n}\right)^{-m}\right]^{2}}{\left[1+\left(\alpha\left|\psi_{m}\right|\right)^{n}\right]^{m \lambda}},
$$

where: $K_{\text {sat }}$ - saturated hydraulic conductivity $\left(\mathrm{cm} \mathrm{s}^{-1}\right)$; $\alpha$ is the inverse of the air entry value $\left(\mathrm{cm}^{-1}\right) ; \psi_{m}$ is the matric potential $(\mathrm{kPa}) ; n, m$ are independent empirical parameters; $\lambda$ is the tortuosity or pore connectivity parame- ter. The Mualem restriction $m=1-1 / n$, and the Burdine restriction $m=1-2 / n$ were compared and the best fitted values (using as criteria the SSQ) was chosen.

\section{RESULTS AND DISCUSSION}

Water content increased due to the addition of biochar, but the effect was more pronounced in the sand than in the sandy loam (Fig. 1). In the sandy control, at matric potentials near saturation, the water loss is higher than in the sandy amendments, traduced in a steeper slope. The range of field capacity increased significantly with higher biochar dosages. With a fraction of 5\% biochar addition, the draining pore diameter between 50-10 $\mu \mathrm{m}$ (Scheffer and Schachtschabel, 2010) increased, and the water content at field capacity also increased significantly. The sandy loam amendments (SL2.5 and SL5) resulted in non-significant differences, compared to the control sample (SL0). Water content at both saturation and wilting point did not increase, but the field capacity range grew (although not significantly) with a higher dosage of biochar.

In the amended sandy soil (S), the addition of biochar decreased the fraction of wide pores related to a matric potential $>-6 \mathrm{kPa}(\varnothing>50 \mu \mathrm{m})$, and increased the narrow $(50-10 \mu \mathrm{m})$ and medium pores $(10-0.2 \mu \mathrm{m})$ corresponding to matric potentials of -6 to -30 and -30 to $-1500 \mathrm{kPa}$, respectively. We hold that these changes came about due to the fill in of pores with the smaller grained biochar, which is also in accordance with the findings of (Ajayi et al., 2016; Ajayi and Horn, 2017). In the sandy loam (SL), the effect of the biochar addition was less evident since the fractions of wide coarse pores were initially similar to the medium and narrow pores.

Biochar and texture affect the pattern of the hydraulic conductivity at different matric potentials (Fig. 2). In the sandy mixtures, the increase of field capacity (on average by $200 \%$ in the observed data), coincided with a more continuous unsaturated hydraulic conductivity pattern $\left(K_{u}\right)$. The higher the dosage of biochar, the more constant 

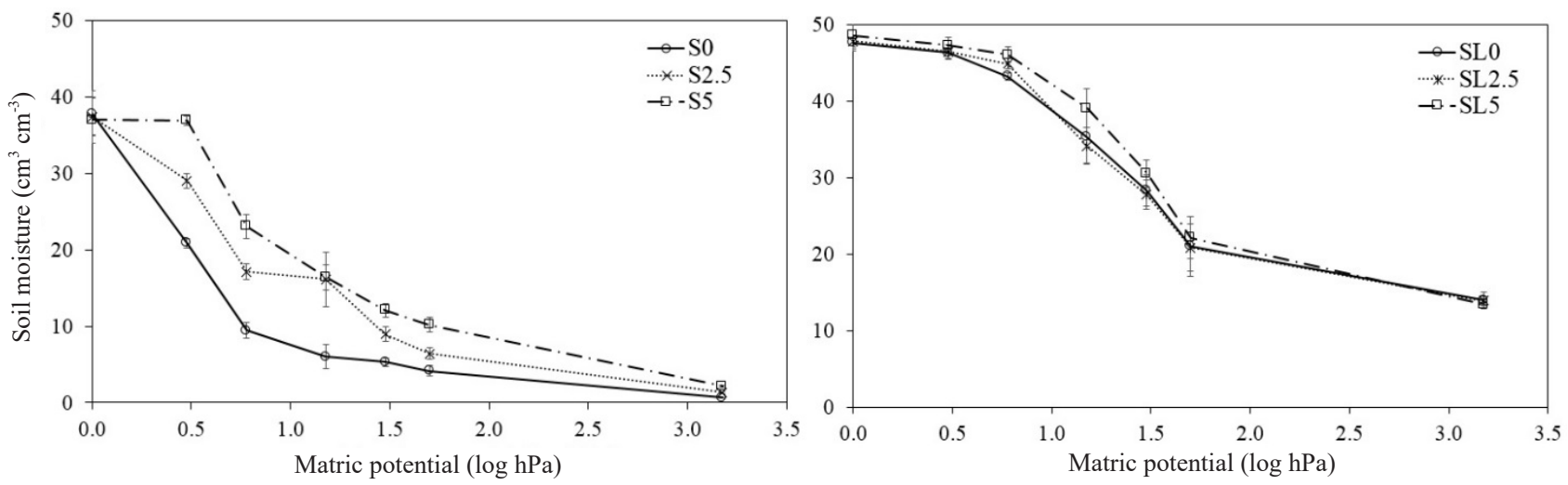

Fig. 1. The measured soil water retention curves of the sand (S) and sandy loam (SL), and their amendments at applications of 2.5 and $5 \%$ of biochar. Error bars correspond to $2 \sigma$ range of the average values recorded at each matric potential, where $\sigma$ represents the standard deviation.
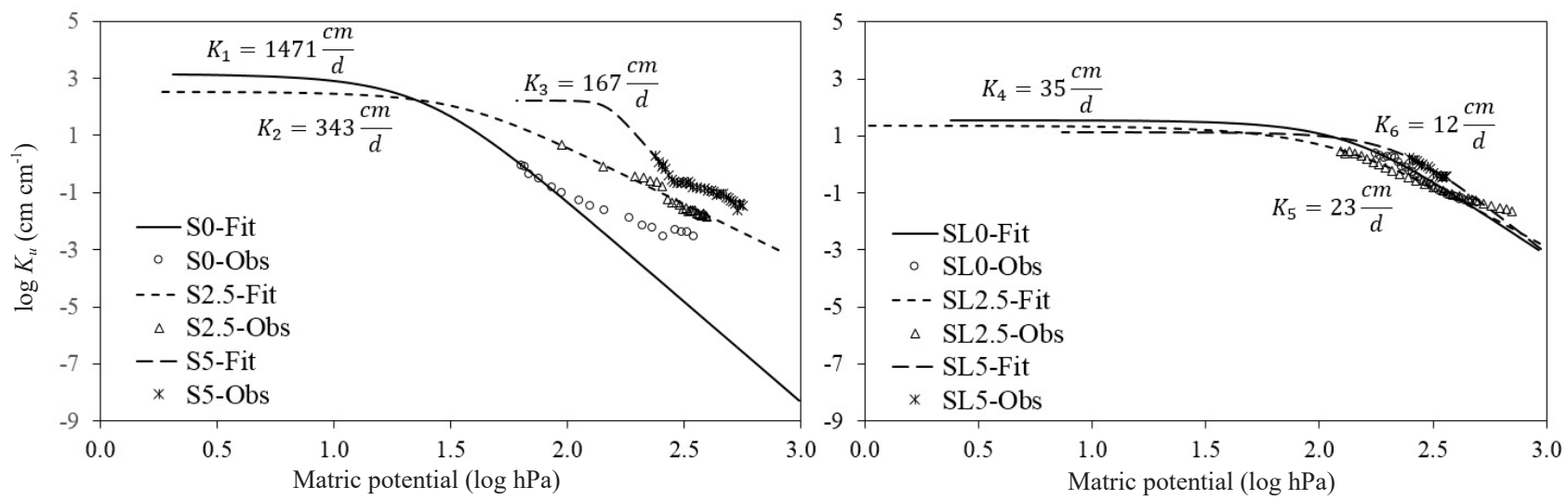

Fig. 2. Fitted and observed unsaturated hydraulic conductivity for the amended sand (S) and sandy loam (SL) with the Mualem restriction applied. $K$ values correspond to the saturated hydraulic conductivity, where the sub-index refers to the treatment: $1=\mathrm{S} 0 ; 2=\mathrm{S} 2.5 ; 3=\mathrm{S} 5 ; 4=\mathrm{SL} 0 ; 5=\mathrm{SL} 2.5 ; 6=\mathrm{SL} 5$.

and relatively higher $K_{u}$ values are obtained up to $-50 \mathrm{kPa}$ (according to the fitting curve). In the sandy mixtures, changes in the field capacity were less pronounced than in the sand control treatment (S0) because biochar increased the frequency of narrow and medium pores, by clogging larger pores with smaller biochar particles, thus enhancing the ability of the amended sand to retain water at more negative matric potentials. Moreover, the sorption capacity of the biochar, due to a higher specific surface area (Table 1), increased water retention at more negative matric potentials, as compared with the unamended sand. The sandy loam (SL) showed relatively constant $K_{u}$ values up to a matric potential of $-30 \mathrm{kPa}$, while the unamended sandy loam (SL0) resulted in a slightly higher (though nonsignificant) $K_{u}$ values, when compared to the amended soil. Finally, the $K_{u}$ curve pattern was relatively flat in the near saturated range but decreased rapidly at more negative matric potentials.

In general, the observed data fitted better via the Mualem restriction $(m=1-1 / n)$ than via the Burdine restriction $(m=1$ $2 / n)$. The SSQ (sum of squares) of the Mualem restriction reflected more accurate values (Table 2). All parameters $(\alpha$, $n, l)$ except $K_{\text {sat }}$ were fitted to the hydraulic curve. $K_{\text {sat }}$ was not fitted since it was determined under laboratory conditions, and the obtained results were reliable enough to be used. Most of the treatments showed good data correlation, except for the SL5 treatment in which the Burdine model provided an unacceptable fit. The fitted $K_{u}$ data of the van Genuchten-Mualem model (Fig. 2) predicted the range of the measured data very well if the decreasing $K_{\text {sat }}$ values, due to the addition of biochar, are included (Fig. 1). The clogging of large pores, especially in the sandy mixtures, through the incorporation of smaller biochar particles, reduced the water conductive capacity under saturated conditions, which was also in agreement with the findings of Obia et al. (2017).

Furthermore, an increase in the surface area (Table 1) of the amended sandy substrates also contributed to relative constant $K_{u}$ values due to the delayed entrance of air in the soil matrix. Although the matric potential at which air enters the sandy loam mixtures was more negative than in the sandy mixtures, $K_{u}$ was not significantly higher when 
Table 2. Soil hydraulic parameters based on the use of the van Genuchten-Mualem model to fit the unsaturated hydraulic conductivity laboratory data shown in Fig. 2

\begin{tabular}{|c|c|c|c|c|c|}
\hline \multirow{2}{*}{ Treatment } & $\alpha$ & $n$ & $l$ & \multirow{2}{*}{$\mathrm{R}^{2}$} & \multirow{2}{*}{ SSQ } \\
\hline & $\left(1 \mathrm{~cm}^{-1}\right)$ & \multicolumn{2}{|c|}{$(-)$} & & \\
\hline \multicolumn{6}{|l|}{ S0 } \\
\hline$m=1-1 / n$ & 0.037 & 2.467 & 1.431 & 0.99 & 0.03 \\
\hline$m=1-2 / n$ & 0.041 & 3.352 & 2.448 & 0.99 & 0.03 \\
\hline \multicolumn{6}{|l|}{$\mathrm{S} 2.5$} \\
\hline$m=1-1 / n$ & 0.024 & 2.778 & -0.880 & 0.99 & 0.03 \\
\hline$m=1-2 / n$ & 0.027 & 3.821 & 0.0001 & 0.99 & 0.06 \\
\hline \multicolumn{6}{|l|}{ S5 } \\
\hline$m=1-1 / n$ & 0.007 & 12.640 & -1.363 & 0.94 & 0.16 \\
\hline$m=1-2 / n$ & 0.007 & 9.538 & 0.0001 & 0.94 & 0.18 \\
\hline \multicolumn{6}{|l|}{ SL0 } \\
\hline$m=1-1 / n$ & 0.007 & 2.648 & 0.0001 & 0.97 & 0.19 \\
\hline$m=1-2 / n$ & 0.009 & 4.171 & 0.0001 & 0.95 & 0.34 \\
\hline \multicolumn{6}{|l|}{ SL2.5 } \\
\hline$m=1-1 / n$ & 0.007 & 2.205 & 0.0001 & 0.98 & 0.07 \\
\hline$m=1-2 / n$ & 0.010 & 3.044 & 0.0001 & 0.98 & 0.14 \\
\hline \multicolumn{6}{|l|}{ SL5 } \\
\hline$m=1-1 / n$ & 0.004 & 3.188 & 0.0001 & 0.98 & 0.01 \\
\hline$m=1-2 / n$ & - & - & - & - & NR \\
\hline
\end{tabular}

$\alpha, n, l$ - fitted parameters; $\mathrm{R}^{2}$ - correlation coefficient; SSQ - sum of squares; NR - poor correlation.

compared to $K_{u}$ of the sandy mixtures. This might also be related to the measured $K_{\text {sat }}$, which was higher for sand and decreased as biochar was added. Between a matric potential of -30 and $-100 \mathrm{kPa}$, the decline of $K_{u}$ in the sandy loam was less pronounced than for the sand. This was due to the presence of finer pores which reduced the draining process and contributed to more water being retained in the soil bulk.

\section{CONCLUSIONS}

1. The addition of biochar enhances the transport of water under unsaturated conditions by reducing the formation of larger pores (draining pores) and promoting finer inter-particle pore formation.

2. In coarse textures biochar increases the water content within the pore diameter in the range of 50-10 $\mu \mathrm{m}$. This enhances the unsaturated hydraulic conductivity for the same matric potentials when compared to the unamended soil.

3. The fill in of larger pores due to biochar addition in coarse textured soils decreases the saturated hydraulic conductivity and increases the unsaturated hydraulic conductivity. This enhances the conductive capacity of coarse-textured soils under drying conditions.

\section{ACKNOWLEDGEMENT}

The first author would like to thank the Laboratory of the Institute of Plant Nutrition and Soil Science of the Cristian Albrechts University in Kiel for letting her carry out the experimental work.
Conflict of interest: The Authors do not declare conflict of interest.

\section{REFERENCES}

AG Boden, 2005. Bodenkundliche Kartieranleitung, 5. Aufl. E. Schweizerbart'sche Verlagsbuchhandlung, Stuttgart.

Ajayi A.E., Holthusen D., and Horn R., 2016. Changes in microstructural behaviour and hydraulic functions of biochar amended soils. Soil Till. Res., 155, 166-175.

Ajayi A.E. and Horn R., 2016. Modification of chemical and hydrophysical properties of two texturally differentiated soils due to varying magnitudes of added biochar. Soil Tillage Res., 164, 34-44.

Ajayi A.E. and Horn R., 2017. Biochar-induced changes in soil resilience: effects of soil texture and biochar dosage. Pedosphere, 27, 236-247.

Bayabil H.K., Stoof C.R., Lehmann J.C., Yitaferu B., and Steenhuis T.S., 2015. Assessing the potential of biochar and charcoal to improve soil hydraulic properties in the humid Ethiopian Highlands: The Anjeni watershed. Geoderma, 243-244, 115-123.

Bodner G., Scholl P., and Kaul H., 2013. Field quantification of wetting - drying cycles to predict temporal changes of soil pore size distribution. Soil Tillage Res., 133, 1-9.

Brockhoff S.R., Christians N.E., Killorn R.J., Horton R., and Davis D.D., 2010. Physical and mineral-nutrition properties of sand-based Turfgrass root zones amended with biochar. Agron. J., 102, 1627-1631.

Burrell L.D., Zehetner F., Rampazzo N., Wimmer B., and Soja G., 2016. Long-term effects of biochar on soil physical properties. Geoderma, 282, 96-102. 
Castellini M., Giglio L., Niedda M., Palumbo A.D., and Ventrella D., 2015. Impact of biochar addition on the physical and hydraulic properties of a clay soil. Soil Till. Res., $154,1-13$.

Dörner J. and Horn R., 2009. Direction-dependent behaviour of hydraulic and mechanical properties in structured soils under conventional and conservation tillage. Soil Till. Res., 102, 225-232. doi:10.1016/j.still.2008.07.004

Eibisch N., Durner W., Bechtold M., Fuß R., Mikutta R., Woche S.K., and Helfrich M., 2015. Does water repellency of pyrochars and hydrochars counter their positive effects on soil hydraulic properties? Geoderma, 245-246, 31-39.

Hardie M., Clothier B., Bound S., Oliver G., and Close D., 2014. Does biochar influence soil physical properties and soil water availability? Plant Soil, 376, 347-361.

Hartge K.H., 1966. Ein Haubenpermeameter zum schnellen Durchmessen zahlreicher Stechzylinderproben. Z. Kult. und Flurbereinigung, 7, 155-163.

Hartge K.H. and Horn R., 2009. Die physikalische Untersuchung von Böden. Schweizerbart'sche Verlagsbuchhandlung, Stuttgart, Germany.

Herath H.M.S.K., Camps-Arbestain M., and Hedley M., 2013. Effect of biochar on soil physical properties in two contrasting soils: An Alfisol and an Andisol. Geoderma, 209-210, 188-197.

Hillel D., 1998. Environmental Soil Physics. Academic Press, USA.

Horn R., 1994. Effect of aggregation of soils on water, gas and heat transport. In: Flux Control in Biological Systems (Ed. E. Schulze). Academic Press.

Instron, 2008. Instron Series 5560A: Reference manual. United Kingdom.

Jury W.A. and Horton R., 2004. Soil Physics. John Wiley \& Sons, USA.

Kameyama K., Miyamoto T., Shiono T., and Shinogi Y., 2012. Influence of sugarcane bagasse-derived biochar application on nitrate leaching in calcaric dark red soil. J. Environ. Qual., 1131-1137.

Lim T.J., Spokas K.A., Feyereisen G., and Novak J.M., 2016. Predicting the impact of biochar additions on soil hydraulic properties. Chemosphere, 142, 136-144.
Neyshabouri M.R., Alavi S.A.R.R., Rezaei H., Nazemi A.H., 2010. Estimating unsaturated hydraulic conductivity from air permeability. Proc. 19th World Congr. Soil Science: Soil Solutions for a Changing World, Australian Society of Soil Science, Brisbane, Australia.

Nimmo J.R., 2004. Porosity and pore size distribution In: Encyclopedia of Soils in the Environment (Ed. D. Hillel). London, Elsevier.

Obia A., Børresen T., Martinsen V., Cornelissen G., and Mulder J., 2017. Effect of biochar on crust formation, penetration resistance and hydraulic properties of two coarse-textured tropical soils. Soil Till. Res., 170, 114-121.

Scheffer F. and Schachtschabel P., 2010. Lehrbuch der Bodenkunde. Spektrum Akademisher Verlag, Heidelberg, Germany.

Selker J.S., Keller C.K., and McCord J.T., 1999. Vadose zone processes. CRC Press LLC, USA.

Soil Survey Staff, S.S., 2014. Soil Survey Field and Laboratory Methods Manual. Soil Survey Investigations Report No.51, Version 2.0.

Uzoma K.C., Inoue M., Andry H., Zahoor A., and Nishihara E., 2011. Influence of biochar application on sandy soil hydraulic properties and nutrient retention. J. Food Agric. Environ., 9, 1137-1143.

Van Genuchten M.T., 1980. A closed-form equation for predicting the hydraulic conductivity of unsaturated soils. Soil Sci. Soc. Am. J., 44, 892-898.

Van Genuchten M., Leij F.J., and Yates S.R., 1991. The RETC code for quantifying the hydraulic functions of unsaturated soils. EPA/600/2-91/065, US Environmental Protection Agency (EPA), Washington, WA, USA.

Van Genuchten M.T. and Nielsen D.R., 1985. On describing and predicting the hydraulic properties of unsaturated soils. Ann. Geophys., 3, 615-628.

Verheijen F., Jeffery S., Bastos A.C., van der Velde M., and Diafas L., 2010. Biochar application to soils: A critical scientific review of effects on soil properties, processes and functions. EUR 24099 EN, Office for the Official Publications of the European Communities, Luxembourg.

Wessolek G., Plagge R., Leij F.J., and Van Genuchten M.T., 1994. Analysing problems in describing field and laboratory measured soil hydraulic properties. Geoderma, 64, 93-110. 